\title{
ALGUMAS CONSIDERAÇÕES SOBRE A TRADUÇÃO DE FINISMUNDO PARA O INGLÊS
}

\section{SOME CONSIDERATIONS ABOUT THE FINIMUNDOS'S TRANSLATION INTO ENGLISH}

\section{Andrea KOUKLANAKIS ${ }^{1}$}

RESUMO: Este trabalho é um comentário sobre a minha tradução de Finismundo: a última viagem, poema de Haroldo de Campos. Dentre outras caracterizações, Finismundo é uma tradução interpretativa do herói Odisseu e de Ulysses. 0 primeiro concebido num mundo pós-clássico; e o segundo enfaticamente pós-heroico. 0 poema é também um comentário indireto sobre a audácia inerente às traduções dos épicos de Homero. Neste sentido, Haroldo implicitamente alude às primeiras traduções da Ilíada e Odisseia para o português, feitas por Odorico Mendes, no século XIX, as quais considera audaciosas e avant-garde (CAMPOS, 1996). Haroldo (1996) escreve que a ideia para a concepção deste poema veio de um estudo semiológico do crítico D’Arco Silvio Avalle (1975). Nesse estudo, Avalle examina o canto 26 do Inferno, onde Dante oferece uma resolução para o enigma da morte de Odisseu: o herói alcançará o paraíso terrestre, somente se conseguir passar pelos limites das colunas de Hércules. Essa gênese do poema, em afinidades com a crítica literária e com alusão ao estilo rococó de Odorico Men-

${ }^{1}$ Doutora pelo Departamento dos Clássicos, Harvard University (2013). Professora de Latim, Bard High School Early College, New York City (a.kouklanakis@post.harvard.edu). 
des, enformou este projeto de tradução. Para um tal texto da poesia concreta, elaborado assim de forma arquitetônica e chamando atenção para as letras e as palavras, eu escolhi adotar um método de tradução o mais literal e conservador possível.

PALAVRAS-CHAVE: Finismundo, tradução, Odisseu, Ulisses, retorno, Odorico Mendes.

ABSTRACT: This paper is a commentary about my own translation of the poem Finismundo which was written by Haroldo de Campos. Finismundo can be seen as an interpretive reading of the hero Odysseus and/or Ulysses. The former is conceived in a post-epic world, and the later in an emphatically post heroic context. The poem is also an indirect illustration of the inherent 'audacity' of translating the Homeric epics. In this regard, $\mathrm{Ha}$ roldo alludes to the first translations of the epics into Portuguese, made by Odorico Mendes in the 19th century, which Haroldo considers both bold and avant garde (CAMPOS, 1996). Haroldo writes that the idea for this poem came from a study on semiotics by the critic D'Arco Silvio Avalle (1975). In this work, Avalle examines Inferno canto 26 , in which Dante offers a resolution for the enigma concerning Odysseu's death. The hero will reach Paradise on Earth only if he manages to pass through Hercules' columns. The genesis of the poem, having affinities with literary criticism and with allusion to rococó style of Odorico Mendes, has determined my translation project. For such a text of concrete poetry, which was elaborated in architectural form and which drew attention to its own letters and words, I chose to adopt a literal and conservative translation method.

KEYWORDS: Finismundo, translation, Odysseus, Ulysses, retorn, Odorico Mendes. 
Eu traduzi Finismundo: A última viagem, de Haroldo de Campos (1990), para o inglês como contribuição para um Festschrift (2012), em comemoração do aniversário de setenta anos do Professor Doutor Gregory Nagy da Universidade Harvard. Portanto, essa tradução foi composta para uma ocasião especial, um fato que necessariamente enformou a abordagem do trabalho, tendo que esta visa um leitor, ou grupo de leitores especializados.

Eu parti da premissa de que Finismundo é, primeiramente, sobre a linguagem poética que reflete ora o herói, ora o anti-herói. 0 poema demonstra um processo de criação ancorado em escolhas de dicção meticulosas e cheias de significação - palavras que apresentam, elas mesmas, várias dimensões, devido às suas construções e derivações morfológicas e semânticas, tais como "multi-ardiloso", multi-artful; "extremo", extreme; "vigilantes", vigilant; "sigilosas", sigilant; "siglas”, signals; "enigma”, "fósforo", phosphorous match-stick, e "semáforo", traffic lights. Por esse motivo, quis manter esse vocabulário intacto na medida do possível, e em todas as instâncias mantive-me o mais fiel possível à linguagem de Haroldo, porque a fidelidade nesse caso possibilitou uma recriação imaginativa na língua inglesa.

Os arcaísmos e latinismos engenham um tom elevado, e ao mesmo tempo promovem o prazer da experimentação verbal e da articulação de sons pouco usuais, prazer este que se nota imediatamente ao se ler o poema em voz alta, como o excerto demonstra:

Odisseu senescente

da glória recusou a pompa fúnebre.

Só um sulco

cicatriza no peito de Poséidon.

Clausurou-se o ponto. $\quad 0$ redondo

oceano ressona taciturno.

Serena agora o canto convulsivo o doceamargo pranto das sereias ( o ultrassom incaptado ao ouvido humano ). (CAMPOS, 1988, p.55) 
Senescent Odysseus

refused the glory of the funereal pomp.

A single mark

scars Poseidon's chest.

Closure is the point. The round

ocean resounds taciturn.

Sing now the convulsive song

the bittersweet lament of the sirens.

(the ultrasound uncaptured by human ear).

(KOUKLANAKIS, 2012, [s.p.])

O inglês, apesar de possuir um léxico com porcentagem significativa de vocábulos com derivação latina, prefere o vocábulo anglofônico, quando há uma opção disponível e adequada e, por isso, foi importante manter as raízes latinas na tradução para preservar a estranheza do poema. Ao mesmo tempo, o uso do latim no lugar da forma anglofônica, pode levar à uma ruptura na compreensão do texto, ou à um tom excessivamente pedante, no lugar de sério, lúdico, ou experimental. Por isso, vez ou outra optei pela forma anglofônica, mesmo quando havia derivação latina, como por exemplo shadowy para "umbráculo", no lugar de umbrated. A escolha de um tema épico, que por própria definição dá lugar preeminente ao estilo da palavra construída de forma especial (poesia), privilegia a tradução literal, preservando assim a autenticidade da concepção original do poema e a autoridade da poesia concreta. Ademais, o estilo formal do poema coincide de forma significativa com a prática da tradução como fase de experimento, processo de criação, recriação e iluminação da linguagem.

Finismundo, porém, mesmo com suas experimentações poéticas não é 'monstruosidade' no mesmo sentido em que críticos de Odorico Mendes referiram-se à sua tradução barroca da Ilíada e Odisseia, uma crítica, aliás, que já há perdeu valor, especialmente com o Haroldo, para quem aquela então chamada 'monstruosidade' é linda por ser autêntica, audaciosa e inovadora, a despeito do (e até por causa de) seu maneirismo 
barroco (CAMPOS, 1996). De qualquer maneira, Finismundo é, ele sim, um poema elegante e erudito, urbano e moderno, análogo à tradição helenística de Callimachus com sua insistência para com a brevidade e erudição na poesia, e com sua atitude poética de distanciamento do canto épico. Esse estilo, lembramos aqui, exerceu grande influência sobre os poetas romanos do final da época republicana, que também valorizavam a experimentação na poética, como Catulo.

Começando já pelo título Finismundo, o poema, constrói um hibridismo entre o latim e o português. 0 poema prossegue com helenismos, latinismos e palavras compostas ("polumétis", "caos pelaginoso", pelagic chaos, "hubris-propenso", hubris-proned, "périplo", "umbráculo", shadowy; "lucerna", lucerne). A linguagem é ornamentada ("escarmentam", scold; "capitoso", commanding; "regaço", captivating bosom), e cria neologismos através da combinação de duas palavras em uma ("extracéu", extraheaven; "maroceano", oceansea; "doceamargo", bittersweet). Na medida do possível, eu procurei manter essa referência obliqua ao estilo rococó, que ademais revela uma certa sensibilidade estética da tradição cultural brasileira, de Odorico Mendes à Carmen Miranda, à arquitetura de Brasília, à poesia concreta, ao tropicalismo. Haroldo de Campos pessoalmente começou a traduzir a Ilíada como forma de homenagem à Odorico (CAMPOS, 1996), alinhando-se assim à uma certa tradição literária e cultural. Esta presente tradução tenta comunicar as práticas haroldianas de produção de poemas, sua erudição, e seu impulso inovador (canibalismo de tradições e regurgitações reconstrutivas).

Finismundo usa como tema o naufrágio de Odisseu, porém com uma cronologia pós-épica, já que o 'tempo' do poema ocorre no período após o retorno do herói a Ítaca. Haroldo constrói esse retorno pós-retorno em termos de ousadia, de contraste entre a esfera doméstica e a aventura pelo mundo afora e, finalmente, como memória e memorialização. Em nível linguístico, vemos uma série de prefixos de negação, contradição, iteração, e frases hifenizadas. 
Ousar o mais:

o além-retorno o após:im-

previsto filame na teia de Penélope.

Ousar

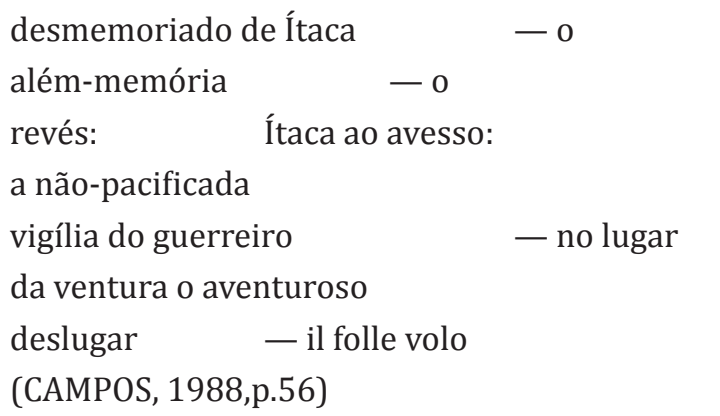

Dare for more:

the beyond-return the thereafter: un-

foreseen thread in Penelope's web.

To dare

unmindful of Ithaca -

beyond-memory - - the

reverse: Ithaca reversed:

the non-pacified

vigil of the warrior

- - in place

of the venture the adventurous

displacement

-_ il folle volo.

(KOUKLANAKIS, 2012, [s.p.])

Essa ousadia de Odisseu é anunciada já no início do poema quando o herói "re-propõe" (re-proposes) a viagem. 0 prefixo iterativo 're' é usado igualmente em inglês, e enfatiza o tema principal da épica: o retorno. De certa forma, Odisseu está continuamente re-propondo o seu retorno, ora de Troia, ora da ilha de Calipso, ora da Feácia , e com o Haroldo, de sua própria Ítaca. A palavra "Último" então ressoa com significados múltiplos, o que inclui o sentido de última viagem em vida, mas também 'consumado' e 'inveterado' viajante. 
KOUKLANAKIS, A. Algumas considerações sobre a tradução de Finismundo para o Inglês

Último

Odisseu multi-

ardiloso - no extremo

Avernotenso limite - re-

propõe a viagem.

(CAMPOS, 1988,p.55)

Ultimate

Odysseus multi-

artful

- - in the extreme

Avernal limit

$-r e-$

proposes the voyage.

(KOUKLANAKIS, 2012, [s.p.])

O tema principal do retorno é trabalhado por Haroldo em duas partes. A primeira trata do Último Odisseu, corajoso e aventureiro, e a narrativa é concebida com linguagem grandiloquente, trazendo ecos da era épica-heroica. As palavras compostas e hifenizadas, mesmo que em sua maioria de derivação latina, evocam também a estrutura do grego homérico, com suas várias ilustrações de adjetivos compostos, tais como polu-metis, sema-phoros, phos-phoros, peri-plous. Não só morfologicamente, mas também ao nível da estrutura, o poema concreto, com sua preocupação com a disposição das palavras na página, evoca a poesia épica, que é também construída assim com blocos de significados, que se movem e se repetem em contextos diferentes, ecos da oralidade que estranhamente se depara com o uber literalismo de Finismundo.

$\begin{array}{ll}{[\ldots]} & \text { Ousar } \\ \text { húbris-propulso } & \text { - o mar } \\ \text { atrás do mar. } & \text { O ínvio-obscuro } \\ \text { caos pelaginoso } & \\ \text { até onde se esconde a proibida } \\ \text { geografia do Éden —— Paradiso }\end{array}$


terreno: o umbráculo interdito:

a lucarna: por ali

istmo extremo insula

se tem acesso ao céu

terrestre:

ao transfinito.

rechaça a pervasiva

- - capitoso

regaço de Penélope

consolação da paz.

Quillha nas ondas

sulca mais uma vez

(qual nunca antes

o irado

espelho de Poséidon: o cor-de-vinho

coração do maroceano.

(CAMPOS, 1988, p.56)

To dare - -

hubris-propelled

- - the sea

behind the sea.

The obscure-pathless

pelagic chaos

towards there where it is hidden the forbidden

geography of Eden - - Paradiso

in terra: $\quad$ shadowy and out of bounds

lucerne: over that way

isthmus extreme island_

there is access to heaven

on earth:

towards the transfinite.

Odysseus senescent

refuses the pervasive

- - captivating

bosom of Penelope

consolation of peace.

Keel on the waves

plows one more time (such as never before)

the irate

mirror of Poseidon: the wine-colored

heart of the oceansea.

(KOUKLANAKIS, 2012, [s.p.]) 
Um outro exemplo de linguagem grandiloquente inclui também a atenção à própria sonoridade das palavras, o que se vê ilustrado pelo poema inteiro. Os seguintes versos oferecem bom exemplo de tais sons e ritmos, o que também tentei captar na minha tradução.

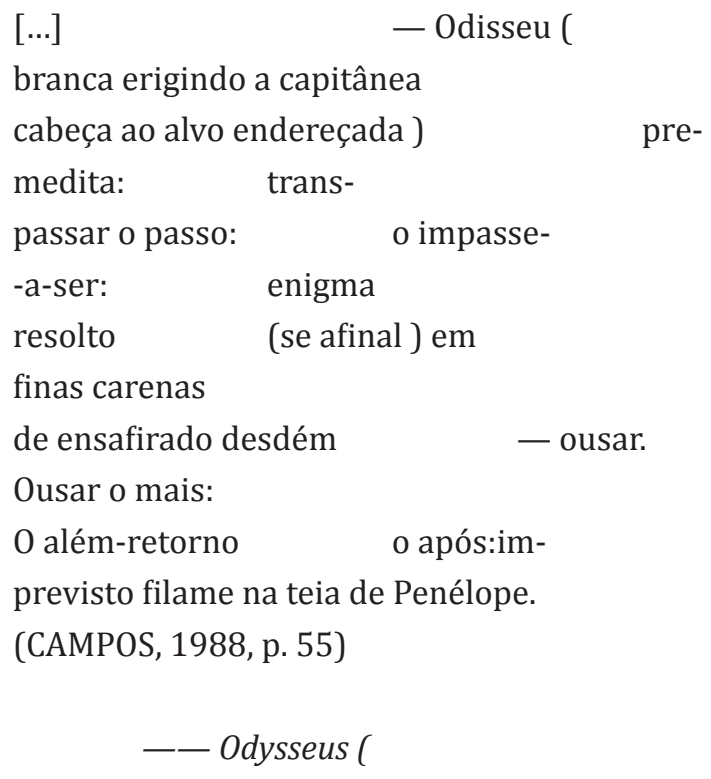

A palavra "capitânea", que traduzi como commanding head, é um vocábulo que ademais nos remete ao apogeu das explorações de navegação portuguesa cantadas e enobrecidas por Camões e vários outros. Demais 
exemplos incluem "húbris", "lares”, "pelaginoso”, formas que caracterizam o Odisseu 'senescente' (senescent), que está ainda comprometido com a aventura ao mar, isto é, com o mundo épico-heroico. 0 mar é o cenário existencial de Odisseu, o sítio de perigo, destruição e naufrágio refletido no "irado/espelho de Poséidon", the irate mirror of Poseidon.

A segunda parte do poema trata do Ulisses moderno, joyceano, concebido como um sobrevivente do mundo cotidiano e prosaico, que transforma em trivial também o seu coração (quotidian heart). A construção poética aqui utiliza uma linguagem que é elevada em dicção, mas que conota o universo mundano e rotineiro:

\section{Périplo?}

Não há. Vigiam-te os semáforos.

Teu fogo prometéico se resume

à cabeça de um fósforo Lúcifer

portátil e/ou

ninharia flamífera.

\section{Capitula}

( cabeça fria)

tua húbris.

Nem sinal

sereias.

(CAMPOS, 1988, ,p. 59)

\section{Périplus?}

There is none. You are watched by traffic lights.

Your promethean fire is summed

with the strike of a phosphorous match-stick

- - Lúcifer

portable and/or

flammable trifles.

Capitulate

(cool head)

your hubris. Not a sign

of sirens.

(KOUKLANAKIS, 2012, [s.p.]) 
A este Ulisses joyceano adiciono também a frase 'Ulisses Haroldiano', já que há elementos nessa parte do poema que carregam um tom local, brasileiro, em termos de ícones culturais, como o 'fósforo', por exemplo, um aspecto que tentei comunicar na tradução. 0 fósforo é o mítico 'condutor de fogo'(phos-phorus) com referência à Prometeu (e Lúcifer, o seu cognado latim), mas a 'caixinha de fósforo' na cultura brasileira é também o condutor do beat popular (urbano e 'vulgar') do 'samba de boteco', como também o cigarro do intelectual e do malandro (este último, aliás, até uma possível definição de Odisseu como um trickster 'multi-ardiloso', multi-artful).

Esse Ulisses moderno contenta-se com a "ninharia flamífera" , flammable trifles, do fósforo. 0 herói joyceano, transportado para um cenário urbano, não entende nem necessita de viagens, e não vive mais para ousar desafios: "Um postal do Éden/com isso te contentas", A post card from Eden/suffices and satisfies you. Nesse mundo de Ulisses, somente restam palavras que uma vez explodiam com significados variados e ricos, mas que são agora "ninharias" (triffles) de sinais. No inglês não há sinônimo com raiz grega ou latina para 'sinais de trânsito', como o 'semáforo' em português, e portanto a tradução traffic lights enfatiza a expressão vernácula e coloquial (ou para brincar com palavras), a frase assume um tom 'pedestre'. De modo geral procurei preservar as palavras gregas e latinas que aludem à uma dicção mito-poética ("prometeico", "fósforo", "Lúcifer"), mas que ironicamente descrevem o cotidiano moderno e banal, tal como "civil/ factótum." Seguindo este mesmo tom e tema, Haroldo então engenha uma morte insignificante para Ulisses:

[...] Teu
epitáfio? Margem de erro: traço
mínimo digitado
e à pressa cancelado.
(CAMPOS, 1988, p.59)
[...] Your
epitaph?




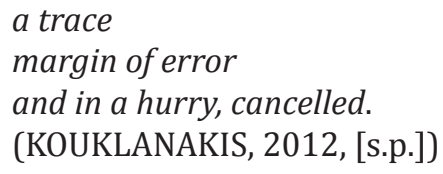

Os dois níveis do poema, então, colocados em tais termos - herói e anti-herói, apesar de apresentarem tensão entre si, estão ambos subordinados ao tema e ideia inicial do poema: a questão do destino de Odisseu, isto é, sua morte. E nessa parte da tradução especialmente tentei atingir um efeito que preservasse a força temática que Haroldo investe no original:

Não conta a lenda antiga

do Polúmetis o fado demasiado.

Ou se conta

desvaira variando: infinda o fim.

Odisseu foi. Perdeu os companheiros.

À beira-vista

da ínsula ansiada

——vendo já

o alcançável Éden ao quase

toque da mão:

os deuses conspiraram.

0 céu suscita os escarcéus do arcano.

A nave repelida

abisma-se

soprada de destino.

não aporta.

O dis se u

Efêmeros sinais no torvelinho

acusam-lhe o naufrágio

instam mas declinam

sossobrados no instante.

Rasuras.

Águas só.

E o fado esfaimado.

(CAMPOS, 1988, p.57) 
KOUKLANAKIS, A. Algumas considerações sobre a tradução de Finismundo para o Inglês

The ancient tale does not tell

of Polumetis and his burdensome fate.

Or if it does

it deceives in variation:

makes infinite the end.

Odysseus went forth.

Lost his compa-

nions

Just in sight

of the island anxiously sought

_- seeing already

attainable Eden almost

within grasp of the hand:

the gods conspired.

The sky raises surges from arcanum.

The ship repelled

into the abyss

blown full with fate.

harbor.

Odysseus does not put to

Ephemeral signs in the whirlpool

point to the shipwreck

impending

but retracting

suspended in the instant.

Water is all. Erasures.

And fate is famished.

(KOUKLANAKIS, 2012, [s.p.])

Ulisses, como já vimos, encontra a morte que vem da absoluta ausência de aventuras e ousadias, articulada como "penúltima" aspiração, penultimate. Por outro lado, na Odisseia, a questão da morte do herói é apresentada com ambiguidade no livro 11, quando o profeta Tirésias diz à Odisseu que o herói não morrerá no mar (thánatos ex halós), se ele agradar Poséidon através de sacrifícios. Haroldo usa a frase grega thánatos ex halós 'morte ao mar', que representa esta ambiguidade ao nível linguístico, já que a preposição $\varepsilon \xi$ ( $e k s$ ) expressa dois sentidos distintos de 'distância' (i.e. longe do mar), ou origem (i.e. que provém do mar). Eu mantive a frase grega, logicamente, já que o próximo verso é efetivamen- 
te sua tradução e repetição, que tematicamente funciona como espécie de refrão.

\author{
Última \\ thánatos ek halós \\ morte que provém do mar salino \\ (CAMPOS, 1988, p. 58). \\ Ultimate \\ thánatos eks halós \\ death born from the salty sea \\ (KOUKLANAKIS, 2012, [s.p.])
}

Se Odisseu morrerá 'no mar' ou 'longe do mar' dependerá da escolha do tradutor do grego para a língua vernácula. Efetivamente Haroldo preserva a ambivalência do grego, mas imediatamente resolve esta ambiguidade em favor da morte "que provem do mar salino", born from the salty sea, adaptando a solução dantesca, em que o naufrágio é inevitável:

Efêmeros sinais no torvelinho
acusam-lhe o naufrágio
instam mas declinam
sossobrados no instante.
Águas só. Rasuras.
E o fado esfaimado. Última

thánatos eks halós morte que provém do mar salino

húbris.

(CAMPOS, 1988, p. 58)

Ephemeral signs in the whirlpool

point to the shipwreck 
KOUKLANAKIS, A. Algumas considerações sobre a tradução de Finismundo para o Inglês

impending but retracting

suspended in the instant.

Water is all. Erasures.

And fate is famished.

Ultimate

thánatos eks halós

death born from the salty sea

hubris.

(KOUKLANAKIS, 2012, [s.p.])

Finalmente, para o Haroldo de Campos, os poemas são "salvos do naufrágio" (1996) e, portanto, cada poema como texto individual, assim como as traduções destes, oferecem versões limitadas, e por isso, continuamente abertas. A presente tradução visa também à uma recuperação destes "salvos", apresentando aqui mais uma variação da lenda. Tal formulação de poema, como resgate de infinitas possibilidades do que fora uma vez, encontra -se poeticamente codificada nos seguintes versos do Finismundo:

Não conta a lenda antiga

do Polúmetis o fado demasiado.

Ou se conta/

desvaira variando: infinda o fim."

(CAMPOS, 1988, p.57)

The ancient tale does not tell

of Polumetis and his burdensome fate

Or if it does

it deceives in variation: makes infinite the end.

(KOUKLANAKIS, 2012)

\section{Referências bibbliográficas:}

CAMPOS, H. Finismundo: a última viagem. Ouro Preto: Tipografia de Ouro Preto, 1990.8 fls. 
KOUKLANAKIS, A. Algumas considerações sobre a tradução de Finismundo para o Inglês

CAMPOS, H. Sobre Finismundo, a última viagem. Rio de Janeiro: Ed. Sette Letras, 1996.

KOUKLANAKIS, A. (tradução.) Finismundo: The Last Voyage Disponível em http://chs.harvard.edu/wa/pageR?tn=ArticleWrapper\&bd$\mathrm{c}=12 \& \mathrm{mn}=4717$ 